\title{
PERSPECTIVES AND OPTIONS FOR THE DEVELOPMENT OF VIRTUAL TEAMS FOR COMMAND OF UNITS IN OPERATIONS
}

\author{
Jiri CERNY, Jaromir PITAS \\ University of Defence, Brno, The Czech Republic \\ jiri.cerny@unob.cz, jaromir.pitas@unob.cz
}

\begin{abstract}
Team cooperation has been one of the crucial elements of effective and successful organization since the late 1960s. Function, structure and behavior within work teams are common part of organizations, firms and security structures. Increasing cooperation across fields, along with tendency to develop horizontal organizational structures, requires the capability to cross geographic and organizational boundaries. Traditional teams are not suitable for this kind of cooperation. With continual invention and application of new information technology, the communication with units during the operations is becoming simpler and faster than ever before. With the development of technologies, command and control has to evolve too. Commanders and staff on the positions of command during operation are not always skilled and informed enough to solve particular problems. The search for new potential will enable the achievement of goals of armed forces during the operations. System of command and control requires new viewpoints and new ways. The solution might be the development of the virtual teams. However, virtual teams are not understood well enough from the practical and theoretical perspective.
\end{abstract}

\section{Keywords: Information and Communication Technologies, Staff, Virtual Team, Command and Control System, Operations}

\section{Introduction}

Contemporary geographic- political environment, in which military operations are conducted, are so diverse and unpredictable, that commanders, with their staffs of various sizes, face many problems in the area of C2. These problems are both military and non-military character. Contemporary security environment is characterized by various nonconventional and conventional threats. When combined, they constitute so called "hybrid threats" and their impact is massively multiplied [1]. With regard to the wide are of operational environment variables, it is necessary to have more persons available, who will have enough knowledge, experience and skills. Commanders have to constantly search for solutions and decisions, for which neither them, nor their staffs can be fully prepared. Military units have to have databases with wide variety of information at their disposal. These databases are used by staffs for the preparation of material for the commanders. The fact is, they do not always find what they are looking for in their standing operational procedures. One of the options for ,promotion“ of the C2 system is the virtual team.

Virtual teams might provide alternative for C2 in future operations. Virtual teams offer both challenges and advantages (i.e. the possibility of commanding geographically dispersed units, radical decrease in the number of members of staff at overcrowded positions of command, decrease in the cost 
of both persons and material, acceleration of the processes...). This modern virtual reality means that with the help of ICT it is possible to make processes of $\mathrm{C} 2$ more effective than they are with the traditional approach.

\section{Goals in the area of $\mathrm{C} 2$ during the operation}

The primary goal of the commanders in operations is to achieve the mission goal. The commander has to plan all the necessary actions, give necessary orders and command his subordinates to achieve the goal. Within the chain of command, commander commands the units even at long distances. But the individual commanders are not able to manage all the various situations, especially during the operations in distant places, in specific environment and with specific mission. They are assisted by staff, which is organized on long-term development. The organizational structure of staff is usually rigid and the team roles are differentiated and divided (usually worked out within standard operational approaches). This also applies for communication flow. The members of staff share the same environment on their positions of command, they meet at briefings, basis, at lunch and this leads to the spontaneous communication, related to work. The respective teams solve clearly defined area of problems during the operations. However, there may occur situations and problems, for which the staff cannot be prepared.

\subsection{The staff, as an advisory body commander}

The experience of recent military operations suggests that the environment in which operations take place are so dynamic and variable that any predictions are almost excluded. The various types of military operations are carried out around the world, with different geographical, hydro meteorological, political, cultural, religious and economic conditions. These facts require continual increase in the available knowledge for commanders and staffs. The innovative application of knowledge for specific environments in the past caused the emergence of a massive use of ICT. ICT stimulated change for the ways of working of commanders and staffs, because knowledge can be not only managed, but also transmitted through the ICT process. Workplace of information worker (or team) can be anywhere, where there is internet connection (offices in peacekeeping headquarters in the country sending the troops, at home, in specialized institutes, in repair businesses, laboratories, ...). This process presents the virtualization of work.

\subsection{Command of the dispersed units}

To command (or for Coordination) subordinate commanders geographically dispersed units, the commander now has technological possibilities to use virtual resources. $\mathrm{He}$ can use video teleconferencing, instant messaging, e-mail, phone, etc. This virtual method of leadership requires above all the respect of certain security policies. The commander has to trust his subordinate commanders, subordinates have to trust the commander. Senior commander cannot convene all his subordinates in one moment (such as is the case in the current operations) and to coordinate their actions with the help of common operational picture. He is not able to pat their shoulders and praise them, not to throw a bad look at them and urge them. He may, however, lead them through the use of electronics. It is not easy for everyone involved, not even for senior commander, who due to age and experience, do not always have confidence in such changes. A number of commanders (mainly senior ones) may not have sufficient knowledge, skills and experience for using the digital media. Virtual reality is environment especially familiar to young people, in the military conditions these are usually at the lowest levels. The operation now can take place directly under the 
"control" of cameras (satellites, UAVs). Commander can with live the fight of his own units without the possibility to personally intervene in any way. He must trust in the ability of their commanders and trust them. Trust is the foundation of virtual work.

\section{Virtual team}

The virtual work can be called such a mode of operation in which the ad hoc formed team (composed of individual experts) performs its tasks by means of ICT, while it may be distanced from the commander and the staff and can be located in any location. This virtual team can be seen e.g. as a small, temporally operating team, geographically, organizationally and (or) in time dispersed information workers, whose work is coordinated mainly via electronic, information and communication technologies and whose purpose is to achieve one or more objectives (completion of tasks) organization. [2]. As a requirement for planning and management of operations, it is possible to assemble highly qualified professionals with different (and non-military) expertise from different sectors and regions of the world into the team. Virtual teams in a military environment can have many variations with regard to focus, field, style of work and actual functioning. E.g. we can talk about a virtual crisis team, which can be assembled in order to accelerate requests of commander in the operation, to solve an acute problem or unexpected situations. To address previously assigned task (to achieve change in a predetermined period of time) it is possible to create virtual planning team. To address diverse and repetitive activities and situations, permanent virtual team (team of consultants) can be assembled. [3] The main reason for using virtual team can be mutual cooperation of a number of people in order to accomplish or create something, which could not be done by any of the teams of staff, located on-site of command in the operation.

\subsection{Characteristics of virtual team and its management}

Virtual team is a kind of team that differs from traditional team (staff type) in:

- spatial distances of the individual members,

- ways of communication. [4]

The spatial character captures the distance between team members. Way of communication is based on technology that transmits images, voice, or text (or all at once). Compared to traditional, virtual team is a team made up of people who are physically separated from each other. Usual face to face style of the communication must therefore be replaced by a communication transmitted by ICT. Operation of virtual teams should not be confused with the concept of reach back, because they are not a groups, teams or specialists from the parent task force, which act as a second part of the space command post on the peacekeeping headquarters broadcaster in the sender's land. Virtual teams should be created for a particular operation, but people in virtual teams are not officially subordinate to the commander of mission. Therefore, many commanders argue with regard to virtual teams, "Why do they want anything of them, when someone else gives them their assignments and their salary?" From the above mentioned you can see the difference between conventional management team (staff on-site command) and virtual team. The staff is controlled authoritatively with physical dominance of the position of commander. In contrast, the commander who manages virtual team should use different methods of virtual control. The current ICT enables the commanders to communicate real-time anywhere in the world, with virtually no time delay.

\subsection{Lifecycle of control of the virtual team}

Lifecycle of control of the virtual team (see Fig. 1) shows the individual steps. The input into the lifecycle is the decision about the creation of virtual team, which is not an 
easy task from organizational perspective. Commander, during the preparation of operation, should identify, analyze and assess the threats and the resultant risks in future operations area and whether his staff is capable to cope with them while exercising the command and control of the army. If commander resolves that the staff does not have the ability to manage these risks, he resolves to create a virtual team. Based on the knowledge of the potential risks, he subsequently formulates objective, which ought to be achieved by virtual team, with regard to benefits (superior goal), for the achievement of which this goal should contribute and requirements and restrictions necessary to build a virtual team.

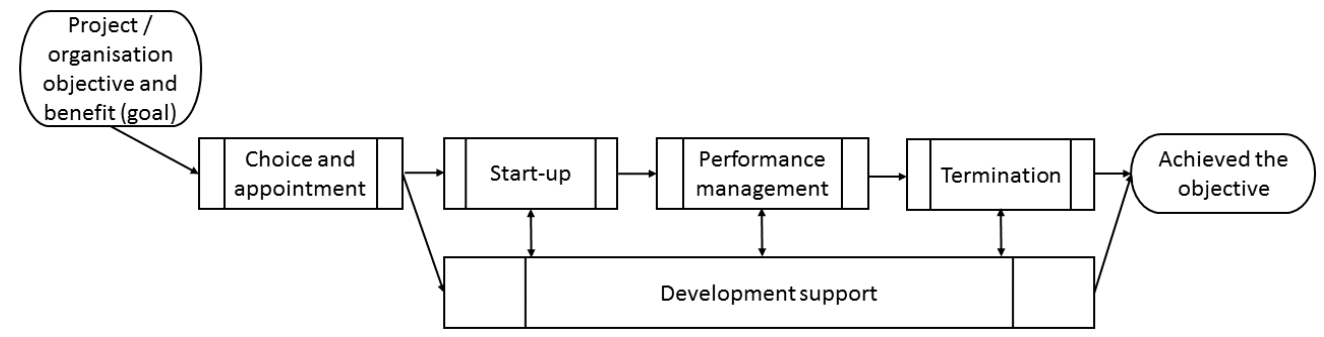

Figure 1: Lifecycle of control of the virtual team

Selection and appointment of members of the virtual team (see Fig. 1) should be implemented with regard to professional qualifications, to the knowledge and experience, bearing in mind that each team member has a specific expertise. Commander (together with senior headquarters) has to define the expertise, knowledge, experience, language skills and security clearance necessary for experts of the team, based on objectives, requirements and constraints of the mission. These experts have to be found before conducting the operation. It can be assumed that experts for specific operating environments and types of operations from the ranks of soldiers and civilians, will be sought in the long term and continuously involved in departmental "personal" database. For civilians, the process should be carried out under the government's long-term agenda, because an important part of work by professionals in virtual teams must be treated legally and intimately linked with the motivation of those working in virtual teams. For professional soldiers the process of activation should be much easier. Buildup of a virtual team should be focused on defining the rules, standards, intends of team role (in the selection of the team of experts) and procedures of work of team commander. Selection and appointment is a very critical step, as the commander may choose people who in a subsequent step, initialization and power management in achieving its objective, will not fulfill his expectations. The commander should consult their concept of creation of a team with experienced staff and senior staff. An important factor for building up a team will be time that the commander has at his disposal. Quick and spontaneous assembling of a team can cause irreversible problems. Commander should approach a greater number of experts, with the same professional profile, than will be needed in the final state. The reason is mainly the fact that after a short (structured) interview, the commander selects the team by personal assumptions about estimation of the role of each individual in the team in the future, and formulates objectives and subobjectives. The commander should assess each adept's qualifications focusing on these attributes:

- moral fitness for a particular role,

- training (professional) capacity for future occupation of role,

- motivation of each individual,

- experience gained from previous similar roles in the team,

- assess possible risks for teamwork. 
The new team, whose members usually do not know each other, should meet at the opening workshop (2nd step of the lifecycle - Initiation see. Fig. 1). Under the leadership of the future commander of the mission, members of the virtual team will become familiar with the goals and objectives of the mission, with space operations and its variables and with rules, processes and methods. Commander should determine the key rules, standards and procedures for the work of virtual team. Furthermore, he should familiarize team members with their roles, with each individual practice, he should present his motivational incentives, while team members should start creating direct links in the team.

Creation of the team should start with its forming, clearing and adoption of objectives, standards, procedures of work, roles in the team - see Figure 2. After its final assembly and preparation, virtual team should attend final phase of preparation of units (preparation of Staff) to be sent into operation (typically within a computer assisted exercise - CAX computer Assisted exercise). Here the commander should examine the work of ICT, knowledge of individual processes, procedures and methods in accordance with the SOP processed. This he does by utilizing the training tasks, followed by analysis of the process. So the commander moves from an initiation of action to the control of a virtual team's performance as shown in FIG. 1. The aim is to confirmation of standardized performance with transition to its growth, in order to achieve desired performance (performing) (see Fig. 2). This activity can also be seen as part of a parallel step of the lifecycle, support of the development of the virtual team (Fig. 2). Participation of virtual team at this preparation of unit is aimed to start and improve the performance of individual members of the project team.

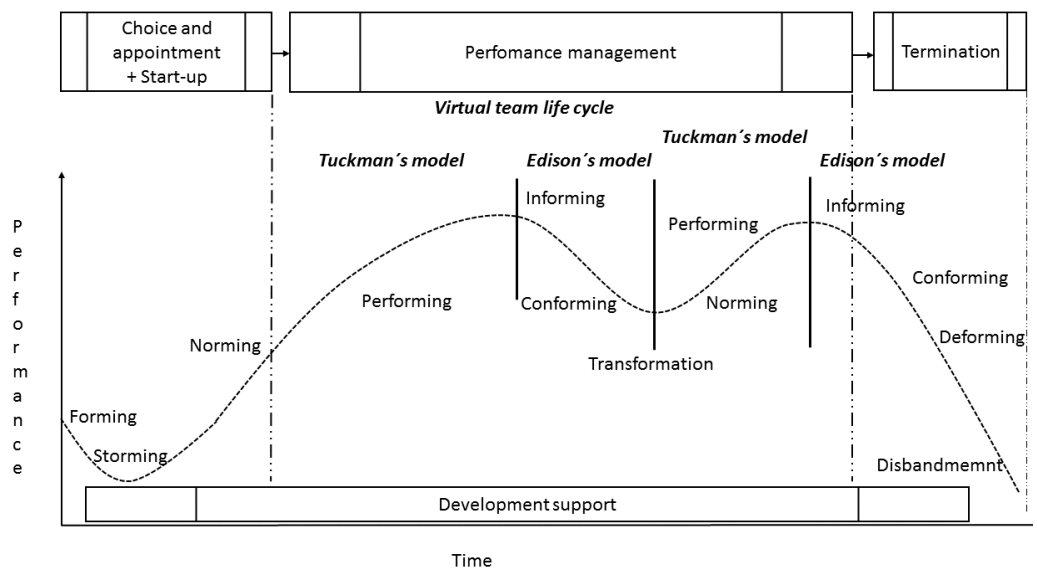

Figure 2: Lifecycle of control of virtual team and the development of the team according to Tuckmen and Edison

In the relatively short time after the completion of the preparation, there should follow performance control as the next step of the lifecycle for the successful achievement of objectives in the implementation phase (performing the tasks of the mission). This step begins when the commander needs to prepare the groundwork for a particular decision or he faces the problem and a virtual team gets specifically task and it starts to solve it. This phase is characterized by the implementation of specific processes (operations) associated with the meeting of the objectives of the mission. Commander remotely (from the area of operation or 
command posts after ICT) uses knowledge and professional qualifications of the individual members of the virtual team, in accordance with the established limits and team roles, to prepare a decision for the prevention and solving of the problem. All his requirements, in accordance with set rules and procedures, are aimed at fulfilling the mission objectives. Virtual team works according to processed SOP. The function of the Commander at this stage consists of setting clear task, setting the parameters of its implementation in accordance with the SOP and having in mind the time that the team was given to complete the task. Compared to conventional Team (Staff) commander, he cannot use the terms "right", "right now," "soon as possible". He must also be aware of the time zones (daynight). What is important to understand in a multinational environment of a virtual team is that the understanding of deadlines is different in every culture. [3]

At the same time, during the implementation phase, the commander may face many with regard the control of virtual team:

- Some team members begin to require more information and this leads to the weight of the more "annoying?" communication in e-mails and telephone (videoconferencing).

- Some team members will work more some less. Those working more may begin to question whether they work for "reasonable" salary.

- While controlling a virtual team, the commander focuses on addressing the challenges of the operational process at place of command a this may lead to gradual loss of interest in solving the problem; individual team members may begin to negotiate with each other and so the main key concept of the solution to the problem may be diverted.

- With the absence of commander's explanation (support for problem solving, evaluation) and subsequent "appeasement" of those members of the team, whose findings cannot be adopted, partial inhibition of activity of the virtual team may follow.

People working in virtual teams usually copy the attitude and behavior of their lead manager - Commander. It is important what style the commander prefers. Cooperation within virtual team will be determined by the "sobriety" of the commander pointing out the best, respectively the worst. Therefore, it is appropriate that the commander appoints his representative, who will support the development of a virtual team from "Home", which means he:

- maintains communication with members of the virtual team,

- continuously analyzes the needs and weaknesses of team members,

- sets training tasks with regard to the situation of the mission, for preparation of addressing the challenges issued by the commander.

Deputy Commander is as a person who supports the development of a virtual team to timely capture the transition of the team development from Tuckmen model to Edison model (see. Fig. 2) and to reduce / maintain the performance of the team at the appropriate level in the course of the mission, together with a readiness to perform tasks issued by commander from abroad. Winding up and dissolution of a virtual team is the final step in the lifecycle control of a virtual team, which should not be overlooked because of its importance to the team members. As commander carries out the assessment (assessment), he has to objectively evaluate the activity of the virtual team (all of its members) and also and get from it the feedback for further improvement of activities of the next lifecycle control of virtual team. It must be understood that both the commander and the individual team members gained new experience to further their professional development and additional motivation to work with a virtual team. Nevertheless, the action of the team is formally ended (must 
be treated with the government's agenda for civilians and with the doctrine for soldiers) and individuals will start to work as ordinary employers.

\subsection{Basic requirements for technological support for the functioning of virtual teams}

A prerequisite for the work of individual members of the virtual team is the access to high-quality ICTS, which should ensure the full work required. At present, a satellite connection is used for the transmission of data and voice during the operations. [7] It is a specific type of connection that allows connection to a long distance high bit rate in a large coverage area. The connection is made by the utilization of communication satellites and it enables secure multichannel connection. Because the communications satellites are expensive, many armies only hire them. USA developed the military satellite system TACSAT. The system consists of geostationary satellites deployed to cover the entire globe. Czech soldiers within the framework of cooperation during the missions used these American satellites. Czech armed forces also have the option to use civilian satellite INMARSAT, which can be used as a converter for access to other connecting systems. For military purposes, three frequencies may be used: Lband $390 \mathrm{MHz}-1.55 \mathrm{GHz}$ (for GPS, satellite telephony around 1.2 to $1.5 \mathrm{GHz}$, for connection with the LEO and MEO satellites), X-band $8-12 \mathrm{GHz}$ (for military or government connections - advantageous ratio of the size of the antennas, profit, routing) and Ka-band $18-40 \mathrm{GHz}$ (for military applications, broadcast $\mathrm{TV}$, and VSAT terminals. With the use of small antennas there are problems with the decline in performance in the rain). Military forces use technology for data transmission called Point-Point or SCPC (single channel per carrier). Connections are formed between VSAT two stations with one satellite jump, i.e. without passing through the central hub station. It is not a network solution with shared satellite channel, but communication in a dedicated zone, i.e. with a guaranteed transfer rate. High quality of connections of SCPC makes them ideal for use by applications sensitive to transmission delays such as IP telephony and video streaming in addition to standard data transfer. [8]

\section{Conclusions}

ICT strongly influences how we work and how we will work in the future. Searching for new potentials and new ways will allow us to better meet the objectives of the military forces, performing missions in operations. Virtual teams, which are trends in today's globalizing world, should become a working standard that develops new tools and methodologies for mutual communication. Knowledge can be transmitted through ICT so it is possible for people to work on remote locations while being in contact with each other. Workplace of the intelligence worker today can be anywhere where he can connect to the Internet. Conversely, any place where the Internet is available, may become a workplace, if the situation requires it.

\section{Acknowledgements}

This article was supported by the project ROZUM DZRO K-105: Development of general and applied the theory of military art and military history research between modern and postmodern wars, supported by the Ministry of Defence of the Czech Republic in the years 2016-2020.

\section{References}

[1] PIKNER, Ivo and ŽILINČÍIK, Samuel. Military concepts and hybrid war. Forum Scientiae Oeconomia, 2016, vol. 4, no. Spec Issue No 1, p. 25-33. ISSN 2300-5947.

[2] NADER, E. A., SHAMSUDDIN A., and ZAHARI, T. (2009). Virtual Teams: A Literature Review. Australian Journal of Basic and Applied Sciences, 3, pp. 2653-2669. 
[3] EVAngELU, J. E. and GRUNDEL, D. (2011). Virtuální tým. Brno: Computer Press. pp. 111-115.

[4] BELL, B. S. and KOZLOWSKI, W. J. A typology of virtual teams: Implications for effective leadership. Group and Organization Management, 2002, vol. 27, no. 1, pp. 14-49.

[5] NEKVAPILOVÁ, I and PITAŠ, J. Factors Affecting Project Management in the Public Sector. In: Conference Proceedings 1. Management and Military Sciences. Sibiu, Romania: "Nicolae Balcescu" Land Forces Academy Publishing House, 2016, p. 211 219. ISBN 978-973-153-245-5.

[6] LIPNACK, J. Virtual Teams: People Working Across Boundaries with Technology. USA: John Wiley \& Sons. 1997. 352 p. ISBN 0471388254.

[7] HRŮZA, Petr; SOUŠEK, Radovan and SZABO, Stanislav. Cyber-attacks and attack protection. In: WMSCI 2014 - 18th World Multi-Conference on Systemics, Cybernetics and Informatics, Proceedings. Orlando, Florida, USA: International Institute of Informatics and Systemics, IIIS, 2014, p. 170-174. ISBN 978-1-941763-04-9.

[8] DVǑ̌ÁK, Zdeněk; HRŮZA, Petr and KASAL, Radan. Automated distance responding to crisis situations in railway transport. In: Proceedings Transport Means 2015. Kaunas (Litva): Kaunas University of Technology, 2015, p. 123-126. ISSN 1822-296X. 